\title{
A CULTURA CORPORAL COMO CONCEPÇÃO QUE ORGANIZA A EDUCAÇÃO FÍSICA E CARACTERIZA O ESCOLAR
}

Rosa Malena de Araújo Carvalho ${ }^{(*)}$

\section{A FORÇA DA ESCOLA PÚBLICA NA CARACTERIZAÇÃO E QUALIFICAÇÃO DA EDUCAÇÃO FÍSICA}

É evidente que sempre falamos de um lugar social e político e dele saem nossas convicções. Mas elas não são as únicas e nem as mais verdadeiras, são apenas nossas, e se tivermos competência para lidar com elas perante nossos alunos, talvez eles venham a aderi-las um dia, não porque são verdades absolutas, mas porque dizem mais e explicam mais sobre a Educação Física e o mundo (COLETIVO DE AUTORES, 2014, p. 179)

Com uma história que vem da instituição militar e médica, a educação física escolar ainda percorre o caminho de consolidar-se como prática pedagógica. No Brasil, é inserida no sistema educacional em momento de profunda reorganização dos tempos e espaços sociais - contexto de passagem do rural ao urbano, no qual a escola recebe as tensões das forças que a querem capturar para a efetivação de projetos e gestos que não são os escolares. Como Professora marcada por uma trajetória acadêmica de viver e indagar essas tensões, esse texto tem objetivo de contribuir para a organização dessa prática pedagógica e, ao mesmo tempo, ao realizar isso, dar a ver o que caracteriza o escolar. Busca-se, assim, pensar a dinâmica dessa prática pedagógica no e com o conjunto da organização escolar. Para isso, partimos da ideia de que a (insistência) para a não caracterização da educação física, como prática pedagógica, faz parte das forças que descaracterizam o escolar e, com isso, a educação sofre os impactos e os interesses de quem não tem o compromisso com essa prática social.

Esse texto desenvolve-se em dois movimentos que se entrelaçam: pensar as características da escola, em especial em diálogo com o livro Em defesa da escola - uma questão pública, de Jan Masschelein e Maarten Simons (2014) e, dar a ver o que a concepção de cultura corporal, conceito elaborado por uma obra reconhecida e catalogada como Coletivo de Autores (2014), contribui para favorecer a organização do trabalho docente dos professores de educação física nas escolas e, na formação docente. Para isso, como Masschelein e Simons, colocamos a escola e essa prática

\footnotetext{
${ }^{(*)}$ Doutora em Educação. Professora adjunta no Instituto de Educação Física da UFF; Coordenadora do Grupo de Pesquisa ELAC (Educação física escolar, experiências Lúdicas e Artísticas, Corporeidades). E-mail: rosamalena @vm.uff.br.
} 
pedagógica em questão, acreditando que as acusações não são direcionadas ao específico da escola e, desejando contribuir com elementos para a defesa e a caracterização do trabalho docente, assim como o necessário para essa materialização.

Masschelein e Simons partem da ideia clássica de escola da antiga Grécia, a qual era considerada tempo livre e fonte de conhecimento, onde a experiência é disponibilizada como bem comum, pois é "o lugar onde a sociedade se renova, libertando e oferecendo seu conhecimento e experiência como um bem comum, a fim de tornar possível a formação" (p. 161). Por isso, em todas as épocas, é olhada com desconfiança e essas transgressões (de tempo e de considerar de todos) são constantemente punidas com esforços de correção (o que gera a ideia de reformular e melhorar...). Argumentam contra a condenação da escola, ideia que tem na questão do tempo e do bem comum seu maior ataque, pois "oferece "tempo livre" e transforma o conhecimento e as habilidades em "bens comuns" e, portanto, tem o potencial para dar a todos, independente de antecedentes, talento natural ou aptidão, o tempo e o espaço para sair de seu ambiente conhecido, para se superar e renovar (e, portanto, mudar de forma imprevisível) o mundo" (p. 10). Tornando o futuro da escola uma questão pública, desenvolvem argumentação, abordando cinco questões, hegemônicas, de acusação da escola: alienação; poder e corrupção; desmotivação da juventude; falta de eficácia e empregabilidade e; demanda de reforma e a posição de redundância.

Indo ao encontro do pensamento que se move nas ideias e gestos de reconhecer que temos um passado, de que há condições históricas que pressionam nossas possibilidades de existência, mas também reconhecendo que há brechas, possibilidades que produzem diferenças no que está prescrito e estabelecido por alguns, a prática pedagógica aqui defendida é aquela que considera seu passado, sem apartar a capacidade de criação e invenção como lentes de ver o mundo - inclusive o passado -, as quais contrapõem os determinismos, os dons, os talentos naturais, as "essências" de cada um. A educação física recebe e, por vezes gera, a força que a colocam como elemento de "condenar" a escola, como dizem esses autores - afinal, não seriam as práticas corporais presentes na escola as maiores expressões de alienação; da falta de eficácia e empregabilidade e; da necessidade e demanda de reforma; assim como sua posição de redundância? E, ao mesmo tempo, como um "outro lado da mesma moeda", em especial os esportes não são àqueles considerados capazes de combater o poder e corrupção, assim como a desmotivação da juventude presente nas escolas?

Mas, exercitando qualificar e a caracterizar essa prática pedagógica por aquilo que define o escolar, questionamos a obviedade dessa questão - por isso, a ideia de escola como aquela que "oferece o formato (ou seja, a composição particular de tempo, espaço e matéria, que compõe o 
escolar) para o tempo-feito-livre, e aqueles que nele habitam literalmente transcendem a ordem social (econômica e política) e suas posições (desiguais) associadas" (op. cit., p. 29), pode apontar indicativos para a escola do futuro. Para isso, Masschelein e Simons respondem com oito ideias ao “o que é o escolar": uma questão de suspensão; uma questão de profanação; uma questão de atenção e de mundo; uma questão de tecnologia; uma questão de igualdade; uma questão de amor; uma questão de preparação e; uma questão de responsabilidade pedagógica (ou exercer autoridade, trazer à vida, trazer para o mundo). Então, mobilizada por essas questões, compartilhando da ideia de "defesa" da escola, ao mesmo tempo apresento como a educação física se constitui nesse universo, como uma prática pedagógica.

Como suspensão está relacionada com os gestos que interrompem, temporariamente, o passado e o futuro - o que significa a força da presença e não a negação do passado, nem das outras dimensões da vida em sociedade, mas as trazem para a escola como objetos de estudos. Nessa ideia, o direito ao estudo, de maneira ampla e geral, auxilia a indagar porque alguns elementos curriculares, como a educação física, são considerados desnecessários por alguns. As experiências com o chamado currículo mínimo, em geral, partem da justificativa de que indicam a menor quantidade de conhecimentos apresentados aos alunos. No entanto, temos percebido que têm sido traduzidos por um oferecimento restrito de áreas, disciplinas e conteúdos. Por isso, preferimos nos referir a conteúdos básicos de todas as disciplinas/elementos escolares, em uma concepção de currículo ampliado - ou seja, composto por todas as disciplinas/elementos curriculares, com o estudo do maior número possível de seus conteúdos e, ao mesmo tempo, que isso signifique intensificar, aumentar o olhar para as coisas do mundo.

A escola como tempo suspenso faz pensar, imediatamente, na Educação de Jovens e Adultos (EJA), onde muitos não tiveram período de infância, pois o tempo livre era um privilégio de outros. Indica interromper, temporariamente, as adjetivações, filiações e associações que constantemente marcam os jovens e adultos - que ingressam ou retornam às escolas. Muitos assinalam os sujeitos desse universo como àqueles que "não deveriam estar mais ali", pois ocupam os espaços que "são das crianças"; "são os mesmos que nunca quiseram estudar” etc. etc., naturalizando essas condições e negando a formação, no Brasil, de uma população filha de escravos de ontem, marcados por trajetória de miséria, exploração, pobreza. Dizer isso é reconhecer que esses jovens e adultos têm direito aos estudos e que, ao exercer esse direito, que é acompanhado de deveres que o estudar carrega, a suspensão como possibilidade de fazer-se presente, sem determinar seu futuro.

Nessa lógica de identificar a escola como presente e meio termo, um espaço e um tempo para possibilidades e liberdades, Masschelein e Simons trazem a ideia de profanação. Tempos, 
lugares, coisas profanadas - qualquer coisa que seja "desligado do uso habitual, não mais sagrado ou ocupado por um significado específico, e, portanto, algo no mundo que é, ao mesmo tempo, acessível a todos e sujeito à (re)apropriação de significado" (p. 39), ou seja, tornou-se público. As coisas tornadas públicas são livremente utilizadas e, por novas maneiras - o que inclui os conhecimentos escolares. E, como o futuro dependerá de qual importância as novas gerações tenham pelo mundo, precisam ser apresentadas ao que existe - por isso falam em atenção e interesse, em vez da motivação. O que também pode acontecer ao jovem e adulto que reconhece a possibilidade do novo, em contraposição às ideias e estatísticas que já formam, a priori, o seu destino. A profanação pode acontecer também com as práticas corporais, quando têm sua forma hegemônica alterada: em muitas ocasiões, por exemplo, quando há contato com jogos de "elite" (como o tênis de quadra), a sua profanação gera outros usos (nesse exemplo, o frescobol - jogo popular brasileiro, derivado do tênis); além de aversões a esse outro (“dessacralizados”) e; estranhamento e medo, quando jovens de periferia, pobres, negros, com corporeidade nada atlética, entram em contato com práticas e espaços públicos considerados de alguns.

Mencionar atenção e interesse, em vez da motivação, é atuar em fronteira, reconhecendo suas diferenças: enquanto a motivação convida a pensar no "eu", no "quem sou"; a atenção e o interesse, pela ideia do que é estudado ser àquele/a que exerce autoridade, traz à vida, traz para o mundo, auxilia a tornar o conhecimento e o objeto estudado presentes, favorecendo pensar no "que faço aqui", “em nome de quê" (e não "em nome de quem”). O escolar, então, se constitui como uma questão de atenção e de mundo - o que associamos com as práticas corporais: o quanto as crianças e jovens se interessam por ela, nos fazendo indagar porque alguns só mencionam que são motivados por e para ela. A organização dessa prática pedagógica, pelo viés da cultura corporal, permite focalizar a atenção dos alunos em algo, o tornando um acontecimento (não uma ferramenta ou um recurso).

Nesse sentido, também há aproximação com essa obra quando Masschelein e Simons definem as tecnologias escolares como técnicas que engajam os jovens, focando sua atenção e apresentando o mundo. Destacando que as regras escolares contribuem para atingir esses objetivos - aqui, mais duas correlações com a educação física: 1) quando mencionam as tecnologias e sua eficácia nos mínimos detalhes, para despertar a curiosidade dos jovens - identifico que as práticas corporais realizam esse movimento, o qual é subutilizado e desqualificado na escola, pelo pensamento hegemônico e; 2) a associação com a ideia de "exercício", como uma tecnologia escolar e, por isso, a possibilidade de readotar o termo (mal dito, banido da educação atual), como também indicam as leituras de Sloterdijk. Exercícios e tecnologias associados à ideia de que 
desativar, momentaneamente, o tempo comum é reconhecer que a escola desempenha papel importante na (des)igualdade social. Para isso, partir da igualdade é algo da ordem prática, que reconhece que todos são capazes - nessa lógica, a escola tem o valor da potencialidade. Nesse sentido, não há tempo "perdido" ou que "passou a hora de aprender" e, partir do presente, da igualdade para aprender, reconhecendo que pode haver diferenciações pelo trabalho no cotidiano escolar, mas não por imposições sociais, por dogmas. Não porque a escola seja ingênua, mas porque na escola é dado tempo aos alunos para praticarem e se desenvolverem.

No entanto, nos discursos sobre o que é o escolar, para que estar na escola, há o predomínio de que prepara para o mundo do trabalho ou para estudos em nível superior. Essa função propedêutica (de preparar para) esvazia o caráter e a qualificação da escola como uma breve suspensão do tempo, o qual permite abertura ao mundo, pelo contato e estudos com os conhecimentos, como bens públicos. Por isso, Masschelein e Simons invertem e perguntam o que é importante na sociedade para trazer ao que se faz na escola, pois o estudo, a matéria são os conteúdos abordados nas escolas (e não habilidades, perfis, competências). "Na escola, o objetivo é focar em algo de perto e em detalhe, se empenhar em algo e trabalhar arduamente nisso. Em outras palavras, é sobre estudar e praticar algo" (p. 91). Estudar como saber o que não sabia antes, "sendo capaz de" (e não para “ter”). E alguns protocolos que caracterizam o fazer escolar, como os testes, podem ser realizados nessa lógica de avaliar o que cada um é capaz de fazer.

Para essa docência, encontramos a caracterização dos Professores como amadores, pois não são apenas especialistas em algo, mas estão preocupados e envolvidos com esse algo, apaixonados por esse algo. Para reconhecermos um amador, esse é revelado pela extensão, intensidade na forma de estar presente no que e como faz. "Enquanto o conhecimento e a competência garantem um tipo de experiência, é a presença, o cuidado e a dedicação que dão expressão à maestria do professor" (p. 78). Esse professor desenvolve a atenção, o interesse, a responsabilidade, porque o amor não pode ser ensinado - aqui, identificamos como se dá, na maioria das vezes, a presença do/a professor/a de educação física nas escolas, pela expressão da alegria, a qual é constantemente minimizada pela justificativa de que é uma atitude ingênua, alienada. No entanto, o interesse, a intensidade e o amor dedicado às práticas corporais, indicam, muitas vezes, a direção ao magistério - o que revela uma força, potencial, de paixão e atenção ao mundo.

Fazendo distinção entre o professor amador e o populista, messiânico encontramos a relação com a responsabilidade do/a professor/a, a qual se traduz em duas tarefas: 1) de que o aluno esqueça o mundo comum, aonde tem uma função, uma obrigação, uma intenção - o que significa esquecer a utilidade e intenções para com o futuro dos alunos, estando atento à sua presença e; 2) 
provocar o interesse pelo e no presente, concedendo autoridade às coisas e as relações com as coisas - ou seja, a atenção não está no/a professor/a e em seu amor pelo que ensina, mas no objeto/materialidade que faz o estudar/ensinar acontecer.

A atenção ao mundo provoca nossa presença, abertura à experiência. Podem, então, as pesquisas significar essa atenção? O que é necessário para isso? Nesse caminhar - e não metodologia como técnica, sem vida, apenas adequando o/a pesquisador/a aos instrumentos -, a pesquisa como experiência (não como verdade) requer atenção, abertura e, guiados/as pelo "que faço aqui", permite mergulhar a atenção, com a delicadeza de quem quer viver a intensidade desse momento, não ficando nele, mas abrindo/tecendo caminhos. Intensidade que move para encontrar as palavras que expressem, sem fechar, escrevendo para alguém, para qualquer um, pois "hablar desde la experiencia y para la experiencia consiste, exclusivamente, en dicerle algo a alguien, como igual, y no como alumno, no como alguien al que hay que explicarle alguna cosa o convencerle de alguna cosa”1 (LARROSA, 2010, p. 115). Ao nos unirmos aos ecos da obra de Masschelein e Simons, como argumentação para favorecer a compreensão do que é o escolar e, ao mesmo tempo, pensar a materialização da educação física nesse espaço social, conduzimos nossas pesquisas como experiência, em um trabalho singular e coletivo realizado na formação docente em um dos raros Curso de Graduação em Educação Física no Brasil que tem currículo voltado ao escolar, e não para academias, clubes e esporte de alto rendimento.

A escola vem recebendo nossos esforços e estudos, por entendê-la um bem comum; por possibilitar exercício da docência que traga a força do servidor público no atendimento às pessoas, em geral, e nas condições de trabalho e; por favorecer que as práticas corporais possam, no espaço escolar, revelar seu potencial de bem público, laico e gratuito. Assim, passamos ao que permite pensar a educação física escolar e a responsabilidade pedagógica desenvolvida com/através dela.

\section{APRESENTANDO A CULTURA CORPORAL COMO FIO CONDUTOR DA ORGANIZAÇÃO DA EDUCAÇÃO FÍSICA ESCOLAR}

(...) Um clássico é um livro que nunca terminou de dizer aquilo que tinha para dizer (...) persiste como rumor, mesmo onde predomina a atualidade mais incompatível (CALVINO apud COLETIVO DE AUTORES, 2014, p. 171)

\footnotetext{
1 “falar desde a experiência e para a experiência consiste, exclusivamente, em dizer algo a alguém, como igual, e não como aluno, não como alguém que há que explicar-lhe alguma coisa ou convencer-lhe de alguma coisa" [tradução nossa].
} 
No exercício de pensar a organização de uma prática pedagógica que se quer presente no espaço escolar, considerando nada trivial pensar os cotidianos escolares, aqui apresentamos a educação física escolar também indagando a obviedade do que é conhecido quando a mencionamos. $\mathrm{E}$, nesse movimento, colocamos em evidência que exercitar o pensamento na materialidade dos gestos pedagógicos de um determinado elemento curricular, requer diferentes atores do cenário escolar. Especialmente quando se quer caracterizar e qualificar o trabalho docente por forças não hegemônicas.

Em relação ao específico da educação física escolar, aqui não entraremos em sua trajetória histórica, mas partiremos do marco que é a concepção de cultura corporal, a qual surge, no Brasil, no final dos anos 80, em pleno momento de abertura política, após vinte e um (21) anos de ditadura civil-militar. Com as inquietações, tensões e forças desse contexto sócio-político, a cultura corporal torna-se referência porque possibilita explicitar que essa prática pedagógica contém objeto de conhecimento, com intenções e objetivos escolares (e por isso sua inserção na escola e sua vinculação com as ideias dessa instituição), deslocando seu foco da aptidão física. Mencionar e partir da cultura corporal requer destacar que essa sistematização foi por um coletivo e que, ainda hoje, esse conceito é destaque na área - por isso, não só justifico a obra com a qual dialogaremos, mas, reconheço sua força mobilizadora. E isso não significa desejar a universalização das ideias, muito menos uma força dogmática, mas identificar elementos, destacando o quanto do escolar essa concepção auxilia a enxergar. A começar por uma pergunta aparentemente banal, quando indagam “o que é uma prática pedagógica”? (p. 50), ao abordar o histórico da educação física.

Em uma área de formação que recebe, a cada ano, inúmeros novos (e jovens) alunos que iniciam sua graduação buscando aprimoramento físico nos esportes, almejando o trabalho como técnicos esportivos e/ou treinadores de alto rendimento atlético, essa pergunta toca, direto, na "ferida". Especialmente quando respondem que "(...) surge de necessidades sociais concretas (...)" (idem) e; já em 1992 defenderam uma educação física como “(...) o trabalho e as relações objetivas materiais reais do homem com a natureza e com outros homens, para o centro do sistema explicativo" (p. 124), ajudando a deslocar a ideia com a qual a maioria dos graduandos chega às Universidades. Para esses autores, então, a educação física é pensada como elemento da cultura.

Falar em cultura corporal não é percorrer o caminho da "idolatria do corpo" ou, de que há, em contraposição ou complementação, uma "cultura mental” ou uma "cultura intelectual”. Mas de um corpo que se faz, não idealisticamente, presente nos cotidianos - o que denominamos de corporeidade (CARVALHO, 2012). Nesse sentido, a formação do/a Professor/a não se orienta por competências e habilidades parciais (o que seguiria a ideia de aptidão física), mas por “determinada 
maneira de vida, uma atitude dedicada em relação à vida que manifesta em sua personalidade e seu relacionamento com a matéria e a nova geração" (MASSCHELEIN; SIMONS, 2014, p. 150), em movimento de abertura ao mundo - como convida a pensar as diversas formas de expressão das práticas corporais criadas ao longo da história.

Assim, percebemos que olhar pelo viés da cultura é considerar os movimentos, provisórios, realizados por homens e mulheres. O Coletivo de Autores (2014) destaca que isso se torna questão de diversas naturezas e, ao colocarem a ideia de cultura corporal, rompem com a aptidão física como fio condutor da educação física, pois entrelaçam a corporeidade com múltiplas relações antropológica, filosófica, biológicas e etc. Ao aproximar com o escolar, percorremos o caminho de identificar sua materialidade nas escolas; em nome de quê; o quê e como abre ao mundo e; de que maneira possibilita interrogar e dar a ver o que fazem os alunos no tempo em que estão na escola. O desafio passa a ser identificar "o que é digno de ser designado um "bem comum”, o que passa no teste de amor pelo mundo e, assim, o que vale a pena liberar para o estudo e a prática e a formação" (MASSCHELEIN; SIMONS, 2014, p. 162).

Talvez, não perder de vista como desenvolvemos a compreensão do escolar ajude a responder esse desafio. Tratando-se da educação física, quando o Coletivo de Autores sugere que o ato pedagógico parta da "contextualização", fazendo compreender, a partir da antropologia, o quanto as práticas corporais estão plenas de sentidos e atributos sociais, já indica pistas para a criação, quiçá criações, de diferentes respostas. Pois o que hoje compreendemos como um exercício corporal ou esporte em forma de luta, por exemplo, outrora teve o significado predominante de defesa e preparação para a guerra. Com isso, destacamos o quanto a educação física pode relacionar-se com a abertura ao mundo, por dois grandes motivos. O primeiro motivo é da potencialidade de sua relação com um pensar pedagógico que seja o de ampliar o conhecimento do mundo, o que inclui a própria noção de mundo.

Aqui, filósofos - como Hannah Arendt (1996) - ajudam a entender que o que existe, o que constitui nossa herança, construída e deixada pelas gerações que vieram antes, não nos chega por testamento (pois esse indicaria a força da transmissão, do tempo contínuo). A cultura em que nascemos e a cultura em geral só podem nos indicar, pois, ao nascer, temos que descobrir e trabalhar para realizar os diferentes tipos de inserção, de entendimento, de relação, de modificação no mundo em que nascemos, pois não chegamos esquipados ou preparados. A criação de hábitos como produção de um ser que nasce incompleto - e que isso pode ser considerado como uma espécie que fracassou, mas o ser humano cai "para fora de seu ambiente e com isso ganha o mundo no sentido ontológico (...). Se o homem está-no-mundo, é porque toma parte de um movimento que 
o traz ao mundo e o abandona ao mundo" (SLOTERDIJK, 2000, p. 34). Um "fracasso" que permite e exige abertura, pois faz compreender que somos incompletos, precisando de cuidados, proteção e aprendizagens para identificar que não estamos determinados ao ambiente em que nascemos e vivemos. A educação, quando percorre o caminho de alargar, pode auxiliar a indagar e construir caminhos alternativos às forças que querem manter grupos e pessoas nos limites de seu ambiente (como os pensamentos únicos, as verdades absolutas).

E, o segundo motivo pelo qual a educação física pode relacionar-se com a abertura ao mundo, é por dar a ver como uma prática corporal, por se constituir no âmbito social, está diretamente relacionada com suas forças e tensões. Mas, ao constituir-se em prática pedagógica, necessita de um conjunto de elementos e circunstâncias para acontecer no espaço escolar e, nessa esteira, nos indagamos qual a materialidade, como prática pedagógica, produz. Essa pergunta nos guia e reaparecerá mais a frente. Antes, queremos destacar a ideia de que, possivelmente, o que constitui e qualifica a educação física escolar, sua contextualização, capacidade de criar atenção e abertura ao mundo, seja impossibilitada, diminuída em uma organização escolar que, cheia das ideias neoliberais - que se constituem no pensamento da verdade incondicional, exclusiva -, prenda o olhar, as ideias, os gestos, através de todas as práticas pedagógicas que a constitui, para o ambiente e as condições em que apenas se reproduz a vida biológica.

Não à toa, quanto mais a educação física escolar é organizada com apoio das ciências humanas e sociais, menos recebe apoio pedagógico, como na EJA, aonde é facultativa ao aluno, com argumentos que mantêm sua base nas ciências médicas e biológicas. E mais, é desqualificada em suas funções escolares, por sua associação com a instituição esportiva, especialmente em momentos como Olimpíadas, Copa do Mundo de Futebol e campeonatos de expressão regional e nacional, cuja repercussão negativa do Brasil ou da região específica faz aparecer na mídia a pergunta: "e o que a educação física tem feito nas escolas?" - com a ideia, ainda presente, de que deveria ser preparatória e identificadora de grandes e expressivos atletas. Selecionadora, portanto, de talentos.

Por mais que tenhamos capacidade argumentativa de que a educação física busca o desenvolvimento humano e não o motor (pois esse traz visão fragmentada e a-histórica de corpo); de que o corpo e as práticas corporais são constituídos nos diversos tempos e espaços sociais (e, por isso requerem aprendizagem, cuidado e atenção para sua manutenção), reconhecemos que ainda se faz necessário tornar claro de qual conhecimento trata. As explicações para isso podem ser inúmeras, por isso, no exercício aqui realizado, correlacionamos a imprescindível identificação e 
explicitação das particularidades dessa prática pedagógica com a urgência de, ao mesmo tempo, especificar o escolar.

A partir da cultura corporal como concepção dos sentidos e da organização da educação física no escolar, essa prática pedagógica pode ser identificada por grandes blocos (lutas, danças, jogos, atividades rítmicas e expressivas, ginásticas, esportes, atividades aquáticas) - o que faz destacar duas questões extremamente escolares: esses blocos são grandes grupos dos conhecimentos (ou conteúdos ou objetos de ensino) de que trata a educação física e; para seu desdobramento, há um tratamento desses (planejamento) no tempo e espaço escolar. Pela noção de cultura, explicita o corpo e as práticas corporais indo além do estritamente biológico (que recebe o apoio da aptidão física, como concepção); como objetos de estudos, os apresenta aos alunos como conteúdos e; no envolvimento atento com esses conhecimentos, os alunos poderão perceber aspectos que também são da história, da filosofia, da antropologia, do artístico etc. Nesse tempo suspenso para o estudo, o tratamento pedagógico desses conteúdos, como parte da organização do trabalho docente que orienta o interesse dos alunos por algo do mundo - não ficando restrito ao que "gosta", "sabe" ou "acha" importante.

Pensar os conhecimentos básicos na escola, na perspectiva de currículo ampliado aqui mencionada, requer expor a materialidade de cada prática pedagógica. Com essa perspectiva, seguimos e finalizamos o texto.

\section{SOBRE A MATERIALIDADE, CONTEÚDOS, FERRAMENTAS E MÉTODOS QUE A CULTURA CORPORAL REVELA NO TRABALHO DOCENTE COM A EDUCAÇÃO FÍSICA ESCOLAR}

Para enfrentar o ataque que vem sendo desferido contra a educação pública, pelas políticas neoliberais, que esvaziam a escola de conteúdos e conhecimentos científicos é necessária uma proposta consistente e coerente (COLETIVO DE AUTORES, 2014, p. 160)

Compreendendo que abordar a educação física, como prática pedagógica no conjunto da organização escolar é falar em currículo, em projeto político pedagógico, em movimento que pensálos é identificar, construir a "materialidade concreta da escola (o edifício, a sala de aula, o quadronegro, mesas, carteiras, etc.), mas também as ferramentas (caneta, livros, giz, lápis, etc.) e os métodos de trabalho (ensaios, conjunto de problemas, exames, etc.), todos os quais objetivam uma espécie de disciplina para focar a atenção do jovem sobre sua tarefa ou coisa específica" (MASSCHELEIN; SIMONS, 2014, p. 122). Também desconfiando de que a dificuldade em entender a sua inserção específica passa por uma dupla descaracterização e desqualificação - dessa 
prática pedagógica e a do próprio escolar, há algum tempo destaco e indago duas formas que identifico fazer parte desse processo: a naturalização da vida e o afastamento da experiência.

O primeiro, a naturalização da vida, com base nas ciências biológicas, mantendo as pessoas em seus ambientes, como disse Sloterdijk (2000), restringem a vida ao significado da reprodução da sua existência e, nesse processo, impedem o entendimento de que aprendemos, de acordo com nossas condições e inserção no mundo, a expressar, valorar, identificar, criar as marcas corporais. Questões como gênero, etnia, volume muscular, idade etc., têm sua força e relevância social ignorada e percebida como questão "natural”. Quando Masschelein e Simons falam em igualdade como uma das marcas do escolar, eles destacam que todos são "capazes de" e, por isso, quando o/a professor/a parte desse princípio, promove rupturas na lógica elitista de colocar, justificar as diferenças criadas como diferenças naturais. Porém, em constante atualização, hoje, a "forma mais sutil de naturalização com um efeito de domação seja o desenvolvimento de talento. Um talento como um conceito se refere às diferenças na predisposição entre os alunos" (p. 117). Talento, dom, desempenho são ideias e gestos presentes na escola e na educação física que se orienta pela perspectiva da aptidão física.

Já o segundo, o afastamento da experiência, desconecta as pessoas do seu presente e contexto, a faz desatenta, sem interesse ao que está no mundo e, ao mesmo tempo, sem conseguir identificar que as forças que atuam sobre nós, formando hábitos, são de extrema magnitude, inclusive para a não atenção, onde tudo parecer "fácil" e "natural", envolvendo diversas situações da vida em sociedade, diversas “esferas”, como apresenta o pensamento de Sloterdijk.

Ao abordar a materialidade da educação física no escolar, considerando que falar dessa prática pedagógica é também pensar o conjunto da organização escolar, pois o desenvolvimento dessa e de qualquer prática pedagógica acontece na materialidade concreta da escola - como trazem Masschelein e Simons -, possibilitando a efetivação do que é o escolar, a partir da sua delimitação e separação do espaço, do tempo, das necessidades e dos interesses que são da família e/ou do trabalho. Tratando-se da educação física, os estudos e experiências vêm destacando que há duas predominâncias de materialidade: a presença exclusiva da quadra, com marcações e materiais de quatro práticas corporais, em sua forma esportivizada (voleibol, basquetebol, handebol e futebol) e; a ausência de espaço específico, cabendo ao professor/a improvisar - o que muitas vezes acontece no pátio da entrada, no espaço do recreio ou fora da escola (praças, jardins).

Esse quadro acarreta dois movimentos hegemônicos: um no qual os/as professores/as que apenas trabalham com a sombra do "quadrado mágico", como apelidamos a restrição às quatro 
práticas corporais acima mencionadas, em sua forma esportivizada. Ao falar em sombra, refiro-me a uma dupla distorção: de escola e de esporte, pois a forma esportivizada, em raríssimas exceções é possível acontecer nas escolas públicas, porque contem objetivos, estrutura, condições e recursos humanos que não estão na lógica do escolar. E, o outro movimento é aquele do/a professor/a que apenas administra conflitos gerados pela tensão entre as condições adversas para a realização de qualquer prática corporal e, o desejo de grande parte dos alunos em realizá-la, inclusive àqueles que não são os alunos da turma (afinal, organizar uma aula em pátio de acesso à escola, por exemplo, significa contar com todos que entram e saem da escola, em horário previsto ou não...).

Assim, pensar os espaços específicos, dessa prática pedagógica que queremos plena de presença e significados, requer diferentes espaços para a realização de diversas práticas corporais (como quadras, salões amplos, piscinas, sala de aula "regular", etc.), em condições (limpeza, ventilação, tamanho adequado ao número de alunos da classe, separada de outros espaços da escola, etc.). O que existe em algumas unidades. Não advogamos aqui, então, nada inovador. Mas, indagamos porque não está como materialidade do escolar e, além disso, o não encontrar essas condições para desenvolver trabalho docente em que os alunos tenham tempo e condições para estudo, não diz respeito somente ao professor/a de educação física, mas de como a escola está adequada aos interesses que são os escolares. Ou, por que está adequada para apenas alguns, em determinadas condições? Ou/e serão os interesses não escolares que dominam o espaço e o tempo escolares?

Sobre as ferramentas - apresentadas por Masschelein e Simons -, como qualquer prática escolar, requer caneta, livros, giz, lápis, caderno, etc., pois toda prática corporal é passível de estudos através da leitura e da escrita. Ao mesmo tempo, a forma de estudos de uma prática pedagógica que tem as práticas corporais como objeto de estudos, requererá outras ferramentas (bolas de diferentes pesos e dimensões, tatames, materiais sonoros, cordas e muitos etc.). Cada conteúdo dos grandes blocos anunciados anteriormente (lutas, danças, jogos, atividades rítmicas e expressivas, ginásticas, esportes, atividades aquáticas) pode ser decomposto, com as formas e gestos que cada um materializa e, ao mesmo tempo, com sua compreensão histórica, filosófica, geográfica, política evidenciada. Ou seja, há maneiras de lutar, por exemplo, em que cada luta tem seus deslocamentos; suas gestualidades (formas de atacar e defender); seu tempo de execução; seu espaço necessário para realização; quais os tipos de pessoas e as situações em que costumava e costuma ocorrer; os instrumentos que acompanham (ou não) o seu desenvolvimento; qual situação social que a faz nascer e acontecer; os registros que foram realizados ao longo dos tempos; as mudanças no tempo e/ou no espaço (pelo uso/desuso; diferenças geográficas e humanas; assim 
como situações que interferem e podem modificá-la - como a forma esportivizada de acontecer, as mídias, o consumo).

Já em relação aos métodos, talvez esse ponto seja o mais delicado, pois há diversas tensões no desenvolvimento da prática pedagógica educação física, pois ainda não há uma clareza organizando-a no escolar (aptidão física? cultura corporal?) e, na sua relação com o conjunto da escola - e como esse coletivo identifica suas funções, os ensaios, os conjuntos de problemas, os exames, as avaliações em geral. Em nome de quê? Para quê? Na perspectiva da cultura corporal, abordando as práticas corporais como conhecimento e, chamando a atenção dos alunos sobre a tarefa ou coisa específica em curso, cada conteúdo da educação física tem diversos subsídios para realizá-lo, a partir do entendimento do que seja a prática corporal em destaque para estudos (como no exemplo das lutas, podemos iniciar por seus deslocamentos e suas gestualidades específicas (formas de atacar e defender)) - o que pode ser realizado de diversas maneiras (a execução propriamente dita, a observação de vídeos, o estudo em livros etc.). E, os ensaios, os problemas, os exames, as avaliações tratam desse objeto de estudos, do que cada um realizou, na atenção que disponibilizou, nas relações que estabeleceu, a partir do realizado (continuando nesse exemplo, o que aprendeu; como realizou/experimentou essa prática corporal em estudo; as questões de gêneros, violências e novas tecnologias que desdobram do estudado). Pois "não podemos extrair das práticas corporais seus sentidos e significados, ou seja, seu conteúdo histórico. O homem não nasceu praticando esporte, muito menos relacionando esporte com saúde" (COLETIVO DE AUTORES, 2014, p. 163).

A realização desse sentido depende da organização dessa prática pedagógica - explicitando as marcas do estudar ao exercitar a prática corporal e, ao mesmo tempo, ampliando o olhar para o mundo, pelas relações dessa prática corporal com outras situações. Essa vinculação da cultura corporal com o mundo, no sentido aqui colocado, com auxílio de Sloterdijk e Hannah Arendt, talvez seja de pouca e difícil compreensão e, por isso, a cultura corporal tenha sua força orientadora diminuída... O problema é que, ao não relacionar-se com a abertura ao mundo, possivelmente percorremos o caminho de manter as atenções nos ambientes e sua reprodução como tal... Permanecemos, assim, naturalizando a vida - abrir ao mundo e ganhar o mundo é contrapor essa ideia, favorecendo a compreensão de que as práticas corporais podem ser um bem público, pois são socialmente produzidas. E, a escola como local público para descoberta e estudo desse bem público, de como lidamos com ele, do que ele nos provoca e, como o relaciono com o mundo.

Assim, essas pistas apontadas pela pesquisa contribuem para um trabalho de formação atento ao conflito fundamental na educação "para todo futuro: a luta entre os que criam o ser 
humano para ser pequeno e os que criam o ser humano para ser grande" (NIETZCHE apud SLOTERDIJK, 2000, p. 41). A escolarização, para ser grande, não cabe ser sinônima de nova domesticação, mas uma possibilidade de suspensão do previsto e prescrito para todos e qualquer um - isso é o caráter público. Nesse caminho, pensar o escolar requer indagarmos e explicitarmos as responsabilidades que assumimos como professores; em nome de quê; como relacionamos nossos gestos pedagógicos com o mundo e; quais exercícios necessários para educar a ser grandes, intensificando a força de um "pensamento da educação que seja, ao mesmo tempo, libertação do passado e abertura do porvir" (LARROSA, 1999, p. 285).

Seguindo esse trilhar, ampliando o olhar para o escolar, para a educação física e para a educação de jovens e adultos (modalidade que exerce autoridade sobre a pesquisadora), também revelamos muito do social (porque esses alunos são o que alguns chamariam "lixo" da sociedade, por exemplo) e, justamente por isso, há que suspender as características não escolares para que o escolar aconteça. Ao mesmo tempo, alguns fenômenos - como a "juvenilização" da EJA, a qual expõe o grande percentual de egressos dos que estão na idade considerada regular, é convite a olharmos ao que é realizado nesse tempo e espaço. O que significa que falar da educação de jovens e adultos requer também falar da escolarização de uma maneira geral.

A compreensão de corpo e práticas corporais, pela perspectiva da cultura corporal, possibilita ser um fio condutor de ações que se entrelaçam: por desnaturalizar os objetos de estudos dessa prática pedagógica; permite aprofundar a caracterização e qualificação de sua inserção no e com o escolar; auxilia a converter elementos sociais em escolares para colaborar com o trabalho de apresentação e ampliação do que identificamos como mundo. O que significa que finalizamos esse momento de formação com mais elementos, mais disposição para refutar lógicas que colocam a escola como frágil, que expõem as incapacidades de seus professores, do não reconhecimento dos alunos, quando estão presentes, plenos diante de nós e da matéria estudada.

E a indagação em relação aos sentidos e às responsabilidades que desenvolvemos em nossos estudos e pesquisas (em nome de quê? de quem? para quê?) permanecem, pois mobilizam, permitindo identificar novas pistas, construir momentâneas respostas, especificar nossas ações pedagógicas, suspender a prescrição e a previsibilidade. Afastar delas seria correr o risco de paralisar o pensamento, impedindo a suspensão do estudar, da pesquisa como forças que escancaram a intensidade da vida e do mundo que se quer maior. Então, seguimos encharcados por elas e, no caso dessa pesquisa, desejando ter contribuído para dar a ver a importância delas para a educação física e o escolar. 


\section{REFERÊNCIAS}

ARENDT, Hannah. La crisis en la educación In: Entre el pasado y el futuro - ocho ejercicios sobre la reflexión política. Espanha, Barcelona: Península, 1996, p. 185 - 208.

CARVALHO, Rosa Malena. Corporeidade e Cotidianidade na Formação de Professores. Niterói: EdUFF/FAPERJ, 2012.

COLETIVO DE AUTORES. Metodologia do Ensino da Educação Física. 2. ed. São Paulo: Cortez, 2014.

LARROSA, Jorge. Habitantes de Babel - políticas e poéticas da diferença. Belo Horizonte: Autêntica, 1999.

Herido de realidade y em busca de realidade. Notas sobre los lenguajes de la experiencia. In CONTRERAS DOMINGO, José; FERRÉR, Nuria. (Comps). Investigar la experiencia educativa. Madrid, Espanha: Ediciones Morata, 2010. p. 87-116.

MASSCHELEIN, Jan; SIMONS, Maarten. Em defesa da escola - uma questão pública. 2. ed. Belo Horizonte: Autêntica, 2014.

SLOTERDIJK, Peter. Regras para o parque humano - uma resposta à carta de Heidegger sobre o humanismo. 3. ed. São Paulo: Estação Liberdade, 2000.

\section{RESUMO}

Entrelaçando com sentidos educacionais que qualificam a docência nas escolas públicas contemporâneas, compartilhamos estudo realizado no período de pós-doutoramento. Partindo da ideia de que a não caracterização da educação física, como prática pedagógica, faz parte das forças que descaracterizam o escolar, no desenvolvimento do estudo identificamos que a escolarização sofre os impactos e os interesses que não são de sua responsabilidade. Nesse processo, em diálogo com Larrosa, Masschelein, Simons, Sloterdijk e o Coletivo de Autores, destacamos as práticas corporais como conhecimentos e a escola como um bem público. Nossas considerações argumentam para a materialidade da educação física que se faz no escolar, em movimento que requer olhar para o conjunto do trabalho docente.

Palavras-chave: Escola Pública. Educação física escolar. Cultura Corporal.

\section{CULTURE CORPORAL AS A CONCEPTION THAT ORGANIZES PHYSICAL EDUCATION AND CHARACTERIZES WHAT IS SCHOLAR \\ ABSTRACT}

Twining with educational senses that qualify the teaching in the contemporary public schools, we shared study accomplished in the period of post-doctoral. Starting from the idea that the no characterization of the physical education, as pedagogic practice, is part of the forces that mischaracterize the that school, in the development of the study we identified that the education suffers the impacts and the interests that are not school's responsibilities. In this process, in dialogue with Larrosa, Masschelein, Simons, Sloterdijk and the Collective of Authors, we highlight the corporal practices as knowledge and the school as a public asset. Our considerations argue for the materiality of the physical education that is done in the school, moving that requires looking for the whole of teaching.

Keywords: Public School. School physical education. Corporal Culture.

Submetido em 02 de agosto de 2016 